\title{
El exilio español en Londres: Heterodoxias de religión y prensa. Blanco White y Felicia Hemans
}

\author{
The spanish exile in London: Heterodoxies of religion and press. \\ Blanco White and Felicia Hemans
}

\author{
Elena María Benítez-Alonso, Universidad de Sevilla (España) \\ marbenfa@yahoo.es|https://orcid.org/0000-0002-2167-144X
}

\begin{abstract}
Resumen
En su cruzada contra el absolutismo de Fernando VII, los exiliados españoles en Londres se sirvieron de la palabra impresa no solo como medio de crítica política, sino también religiosa en la construcción del Estado liberal español. Aunque un tanto obviado en lo referente a esta cuestión heterodoxa al ser considerado periódico político, El Español de Blanco White abrirá paso, como pionero en la prensa española del exilio londinense, al tratamiento del aperturismo religioso como pilar esencial en el discurso liberal de los emigrados, que después desarrollarán otros refugiados con cabeceras protestantes impresas en español. En interconexión con coetáneos ingleses, como Dickens o Felicia Hemans, la crítica religiosa de Blanco, basada en una continua búsqueda de la verdad, se extenderá además a la prensa inglesa con sus Letters from Spain, aparecidas inicialmente en el New Monthly Magazine de Thomas Campbell, en el que Hemans publicará los poemas que estructurarán su referente contra la intolerancia católica, The Forest Sanctuary, según la propia autora, su mejor trabajo. El análisis historiográfico de esta investigación se centra en el estudio bibliográfico y crítico de los textos sobre la temática expuesta y sus fuentes hemerográficas, con el fin de destacar la aportación de la hibridación religiosa entre la obra periodística de Blanco y Hemans, en el contexto de una misión que desempeñará un papel esencial a favor de la libertad religiosa y que se notará en el incipiente rupturismo de la ortodoxia católica en la obra periodístico-literaria del XIX español.
\end{abstract}

Forma de citar:

Benítez-Alonso, E. M. (2019). El exilio español en Londres: Heterodoxias de religión y prensa. Blanco White y Felicia Hemans. Ámbitos. Revista Internacional de Comunicación 43(1), 115-134. doi: 10.12795/Ambitos.2019.i43.06 


\begin{abstract}
Spanish exiles in London used the printed word not only as an instrument of political criticism, but also as religious criticism in the construction of the Spanish liberal state. Although somewhat overlooked in relation to this heterodox issue because of being considered a political newspaper Blanco White's El Español will open, as a pioneer in the Spanish press of the exile in London, to the treatment of religious openness as an essential pillar in the liberal discourse of the emigrados, which will be developed by other refugees with Protestant mastheads printed in Spanish. In interconnection with English contemporaries (Dickens or Felicia Hemans), the religious criticism of Blanco, based on a continuous search for the truth, will also be extended to English press with his Letters from Spain, initially published in the New Monthly Magazine, in which Hemans will publish the poems that will structure her referent work against Catholic intolerance, The Forest Sanctuary. The historiographical analysis of this research focuses on the bibliographical and critical study of the texts on the subject matter and its hemerographic sources, in order to highlight the contribution of religious hybridization between the journalistic works of Blanco and Hemans in the context of a mission in favor of religious freedom and that it will be noted in the incipient breaking off from Catholic orthodoxy in the journalistic and literary work of the Spanish nineteenth century.
\end{abstract}

Palabras clave: Prensa, exilio, liberales, Londres, religión

Keywords: Press, exile, liberals, London, religion

\title{
1. INTRODUCCIÓN
}

Desde que en el pasado siglo viesen la luz investigaciones pioneras como las de Vicente Llorens $(1954)^{1}$, aunque contando con el precedente decimonónico de Menéndez Pelayo y su Historia de los heterodoxos españoles ${ }^{2}$, el exilio de los españoles liberales en Londres durante los años de la persecución absolutista auspiciada por Fernando VII y propiciada por el ultraconservador entorno político-religioso en un margen más amplio, que en casos como el de José María Blanco White se adelanta y en no pocos otros se prolonga en el tiempo, ha sido objeto de estudio desde muy diversas ópticas. La particularidad de una emigración que, a pesar de ser menos relevante en cuanto a su número con respecto a la de los españoles marchados a Francia, resultó, por su composición social y entorno, bastante más significativa en lo referente a su producción cultural, así como por su activismo ideológico, ha centrado investigaciones multidisciplinares, como las de carácter sociológico y de género llevadas a cabo en las últimas décadas, revalorizando también desde esta nueva óptica la francesa (Sánchez-Mantero, 2010, 
1975; Rubio, Rojas y Fuentes, 1998). En este sentido, a la luz de las nuevas perspectivas que brinda esta reciente historiografía, surge como importante objeto de estudio el papel de la mujer en apoyo de su patriótica causa independentista y liberal, así como la difusión de sus ideales desde el exilio en la primera mitad del siglo XIX, sirviéndose para ello, en numerosas ocasiones, de diversidad de publicaciones (Fuentes y Garí, 2014; Cantos-Casenave, 2016).

La producción periodístico-literaria que surge como fruto de la interrelación anglo-hispana, primero a través de la alianza frente a la invasión napoleónica y posteriormente a causa del exilio español en Londres (Durán de Porras, 2008; Varela, 2016), es uno de los aspectos que profundizan en el papel político desempeñado por medios y autores, algunos de ellos no especialmente conocidos o analizados convencionalmente desde la perspectiva más literaria de movimientos como el romanticismo. En lo que respecta a esta cuestión, la figura de la mujer, no estudiada tradicionalmente por la historiografía, ni cuantitativa ni cualitativamente de forma equitativa, adquiere así además un protagonismo esencial, al contemplarse dentro del ámbito metodológico postulados que favorecen un enfoque antropocéntrico, en detrimento de las habituales interpretaciones androcéntricas predominantes en el estudio del pasado (Saglia, 2000; Calvo-Maturana, 2004; Coletes y Laspra, 2013).

Junto con los estudios centrados en el análisis periodístico-literario, desde una perspectiva más específicamente histórica, otros autores han analizado profusamente la problemática de la represión de los liberales españoles y el exilio decimonónico (Sánchez-Mantero, 2002, 1993; Moreno-Alonso, 2009, 1997, 1989a), especialmente a través de la figura de Blanco White (Moreno-Alonso, 2014, 1989b,1984) y sobre todo a partir de los estudios de Juan Goytisolo, que imprimieron una característica pero errónea interpretación antirreligiosa en la obra de Blanco que merece ser replanteada (Durán-López, 2016, 2010, 2006, 2005). Otros nombres emblemáticos de este exilio español en Londres han sido recientemente objeto de análisis, como sucede con el conde de Toreno (Varela, 2005), encuadrándolos en el peculiar contexto político dentro del panorama español y europeo del periodo. Con respecto, asimismo, a Blanco White y a su contexto histórico, especialmente en lo relativo a la problemática religiosa, partimos de los estudios ya clásicos realizados por Seco-Serrano (1993), Garnica (2002, 1993) o Reyes-Cano (2001), que aborda, en su caso, un perfil más literario, para conocer así en detalle la multiplicidad de aspectos que entraña la figura del periodista y escritor sevillano como uno de los personajes emblemáticos en el contexto anglo-hispano del exilio liberal español decimonónico.

Asimismo, en lo referente a la dimensión cultural y, en particular, al análisis de la producción periodística y literaria del exilio, encontramos otros interesantes trabajos que han visto la luz en 
los últimos años (Durán-López, 2015; Muñoz-Sempere, 2005; Taylor, 2011; Ruiz-Acosta, 2016; Loyola y Flores, 2018) abordando, entre otras, cuestiones como el detallado estudio de los títulos publicados por los liberales españoles emigrados a la capital británica, así como los de aquellos que, provenientes de territorios procedentes del colonialismo español, se desplazaron también a Inglaterra en busca de ayuda para consolidar su defensa del proceso independentista frente a la metrópoli, auspiciándose de este modo en Londres, durante las primeras décadas del siglo XIX, un contexto propicio para el florecimiento de numerosas cabeceras redactadas por españoles y americanos en español, tratando preferentemente asuntos políticos, culturales o religiosos, estando esta cuestión íntimamente ligada a la defensa de la causa liberal.

\section{METODOLOGÍA Y OBJETIVOS}

En este contexto interdisciplinar, la investigación aquí presentada trata de revalorizar el papel de las publicaciones de los españoles en el exilio londinense de la primera mitad del XIX, no solo como medio de crítica política hacia el régimen borbónico, sino como arma eficaz para batallar en pro de la construcción de un Estado liberal español a través de la desestabilización de la tradicional alianza monárquica con la Iglesia, sirviéndose del extraordinario potencial que les brindaba la libertad religiosa que encontraron. Para ello, mediante una exhaustiva revisión bibliográfica y hemerográfica, nos centramos en la perspectiva religiosa de la obra periodística de Blanco White en el exilio y, en concreto, en el análisis de sus artículos en el que es su referente como cabecera de los emigrados, El Español (1810-1814), considerado convencionalmente periódico político, si bien tratamos de destacar la importancia de la exégesis desde la interpretación de su crítica religiosa. Asimismo, recurrimos a la aplicación de esta misma lectura para sus Cartas de España, publicadas originariamente en inglés (1821-1822) en el New Monthly Magazine, periódico editado por Thomas Campbell y que contemplamos especialmente por su apoyo a la causa de los emigrados españoles.

Desde esta óptica, resulta fundamental el estudio de la interconexión entre el aperturismo que conlleva la heterodoxia presente en la obra periodística de Blanco y el de las publicaciones que su coetánea inglesa Felicia Hemans realiza en la cabecera de Campbell desde 1823 a 1825, con las que articula la definida por ella misma como su obra más relevante, The Forest Sanctuary (1825), crítica del catolicismo reaccionario que ambos autores diseccionan en el contexto de un liberalismo religioso del que surgirán posteriormente, ya a mediados de siglo y también de la mano de los exiliados españoles en Londres, las primeras revistas protestantes publicadas en castellano, ejerciendo todo ello una progresiva influencia heterodoxa en la producción periodísticoliteraria de la España decimonónica. 


\section{SOMERS TOWN Y LA CUESTIÓN RELIGIOSA: DE BLANCO A DICKENS}

Los primeros emigrados a Londres descubrieron en la capital inglesa un paraíso liberal al que ya había acudido como precursor del destierro que se avecinaba Blanco White, autoexiliándose en 1810, como él mismo relata en sus memorias ${ }^{3}$, más por causas religiosas que por convicciones políticas. Es a su llegada cuando pone en marcha El Español, que surge así como cabecera pionera de las publicadas en Londres por los liberales españoles y que iría mostrando una evolución en consonancia con la del propio autor, del radicalismo al moderantismo, manifestando influencias del utilitarismo liberal de Bentham y del liberalismo conservador de Burke.

Y es que la oposición al absolutismo fernandino como razón de ser del exilio decimonónico español en Londres se acentuó inevitablemente con la presión del catolicismo reaccionario legitimizado tradicionalmente por el poder monárquico, y custodiado a fuego y espada por la Inquisición, lo que determinó el destierro de no pocos emigrados. Ante ellos, Londres se presentaba como un edén de tolerancia frente a la cerrazón de una España que será objeto de la crítica de Blanco en sus publicaciones periodísticas y literarias contra el catolicismo jerárquico español, refiriéndose, por ejemplo, a la mezcla de orgullo y superstición impuesta por la interpretación de la religión que hace el clero, o a la situación de represión intelectual de periodistas y pensadores críticos. Frente a esta situación, Londres brindaba no solo su asilo político, sino también la oportunidad de poder desarrollar una producción cultural con la que batallar por derribar los pilares del régimen absolutista, además de la obtención de ayuda económica del gobierno inglés ${ }^{4}$ y el apoyo por medio de personalidades como los Holland ${ }^{5}$, para quienes Blanco trabajó como secretario personal del lord y tutor de sus hijos.

Y así fueron llegando los liberales y las "liberalas" ${ }^{6}$ que también las hubo, a tierras inglesas, aunque también a Francia y otros destinos, en menor medida, como Marruecos. Aunque Blanco había llegado a Inglaterra en 1810, la primera emigración significativa de españoles del exilio decimonónico en Londres se produciría tras la restauración del absolutismo fernandino en España a partir de 1814 y hasta 1820, en lo que vendría a ser el primer gran periodo de represión liberal. Desde 1824, no obstante, coincidiendo con el destierro posterior al Trienio Liberal, se produciría una emigración más significativa que se asentaría de forma habitual en el viejo Londres, al norte de la ciudad, en el nuevo Somers Town ${ }^{7}$ que, a finales del XVIII, también había acogido a Mary Wollstonecraft, pionera vindicadora, en pleno radicalismo liberal de la Revolución francesa, de los derechos de la mujer.

En Somers Town viviría hacia 1823, asistiendo pues a lo que sería el inicio del auge del exilio liberal español en la zona, Charles Dickens, en una época en la que el hoy céntrico barrio se 
erigía aún como uno de los suburbios más pobres de la ciudad, pero con una capilla católica de reciente construcción, Saint Aloysius ${ }^{8}$, detalle importante para los españoles ya que, a pesar de la oposición liberal por el control que la jerarquía eclesiástica ejercía en España, entre los exiliados había, no obstante, quienes no se habían alejado del catolicismo en lo referente a su esencia, al margen de la sistemática tergiversación llevada a cabo por el clero. Las calles de este muy español Somers Town de las primeras décadas del XIX serían pues escenario de los frecuentes encuentros entre los refugiados liberales con el aún niño Dickens. De ahí que el novelista inglés evocara años después la imagen de aquellos españoles que solían pasearse envueltos en sus capas y fumando sus cigarrillos liados en papel (Dickens, 2012: 732) ${ }^{9}$, lo que marcaría ese periodo de su infancia en el contexto de una dura convivencia con la pobreza que reflejaría en sus obras más representativas, nutridas también de su arduo proceso de reconstrucción espiritual.

$Y$ es que, como Blanco, Dickens, definido por su hijo Henry Fielding como un hombre de profundas convicciones religiosas (Colledge, 2012: 24), atravesó, ya en la edad adulta, un proceso similar de continuas conversiones. Blanco, como "Peregrino de la Religión"10, inmerso en un proceso de transformación espiritual en permanente búsqueda de la verdad que le acompañará hasta el final en sus sucesivas conversiones dentro del cristianismo, pasó del catolicismo al protestantismo y, a su vez dentro de este, principalmente, por el anglicanismo y el unitarismo hacia una espiritualidad cristiana pura y libre de toda contaminación clerical. En el caso del autor inglés, su particular peregrinaje le llevó a perseguir el verdadero espíritu cristiano por medio del anglicanismo, aunque durante un periodo también mostró interés por el unitarismo, como refieren, además de Colledge (2012), Walder (1981) o Ackroyd (1990). Su formación protestante le condujo, además, a mantener una actitud crítica con el catolicismo y, como Blanco, a mostrar su rechazo ante la hipocresía de la religiosidad institucional y ante cualquier manifestación mundana que considerase una desviación del auténtico espíritu cristiano. En su recorrido por tierras italianas, el catolicismo se le había manifestado a Dickens como la encarnación de una manifestación dictatorial, institucionalizada y supersticiosa del cristianismo, que con su actitud enviaba a la mayoría de sus seguidores a la pobreza, la enfermedad y la ignorancia, mientras que privilegiaba a la pequeña élite de su jerarquía, lo que refleja un claro paralelismo con los planteamientos expresados por Blanco en su obra periodística, teológica y literaria, y que desmenuza también al detalle en su autobiografía. Muestra de este común ideal cristiano, por el que Tolstoy y Dostoevsky se referían a Dickens como "that great Christian writer" (Ledger; Furneaux, 2011: 318; Watts, 1976 : $55)$, hacia 1846, el novelista y periodista inglés escribiría The Life of Our Lord ${ }^{11}$ para instruir a sus hijos en el cristianismo, mostrando su cercanía al unitarismo en su concepción de Cristo no solo 
como salvador, sino también como maestro, sanador, líder ético, un Cristo del Nuevo Testamento que predicó el perdón y un concepto de tolerancia que lo aproxima al ideal liberal defendido por Blanco. La obra refleja además su percepción de la misión social de la religión cristiana como su función principal, a través de un humanitarismo común basado en el altruismo sin exclusión, que se evidencia en su popular A Christmas Carol (1843).

Pero más allá de este paralelismo religioso entre las obras de Dickens y Blanco, encontramos, dentro del complejo entramado de interrelaciones que propició la producción periodístico-literaria de los liberales españoles emigrados a Londres, una interesante correspondencia (además de la epistolar ${ }^{12}$, que también la hubo) entre la obra del autor sevillano y la de su coetánea inglesa Felicia Hemans, en lo referente a la cuestión política del liberalismo y, en especial, a la religiosa, en la que se pone de manifiesto la interconexión fruto del florecimiento cultural resultante del encuentro anglo-hispano del exilio.

\section{EL APERTURISMO ESPIRITUAL DE BLANCO Y HEMANS}

Primeros años de la década de 1820. New Monthly Magazine que Thomas Campbell dirige desde 1812 manifestando su firme adhesión a los liberales españoles. En la que es una de las más relevantes cabeceras de este "centro intelectual de España y aun de Hispanoamérica" (Llorens, 1979: 288) en el que se convirtió Londres por aquel entonces, confluye la obra de Blanco y de Hemans como dos grandes defensores de la causa de los emigrados. El New Monthly Magazine es punto de encuentro entre la doble perspectiva liberal política y, especialmente, religiosa vertida por Blanco como Leocadio Doblado ${ }^{13}$ en sus Letters from Spain ${ }^{14}$ (publicadas originariamente en el periódico inglés desde abril de 1821 al de 1822 por encargo de Campbell) y la reflejada en la obra periodístico-literaria de Felicia Hemans, la poeta más leída en el mundo angloparlante del siglo XIX, publicada en buena parte en esta revista. La interrelación textual entre Hemans y Blanco, con el que la autora consolidaría durante sus últimos años en Irlanda ${ }^{15}$ la amistad nacida de su admiración por las inglesas Cartas de España, se manifiesta, en el terreno de lo político, en la evolución que experimenta Blanco hacia el moderantismo tras su exaltación inicial en El Español como firme detractor del despotismo napoleónico y borbónico, así como en la ferviente lucha contra la tiranía que acomete Hemans, defensora de un patriotismo liberal que plasma ya en su temprana producción a favor de la alianza anglo-hispana contra el dominio francés (England and Spain; Or, Valour and Patriotism, de 1808) o en la póstuma Records of Woman (1836), en la que la figura de Espoz y Mina le sirve de inspiración dentro del "corpus hemiano" relativo a la causa patriótica liberal española (Coletes y Laspra, 2013: 39). Es, no obstante, en lo religioso, donde las críticas reflexiones sobre el fanatismo de la ortodoxia clerical católica de las Letters 
from Spain se convierten en objeto de fascinación de Hemans (Sweet, 2010), observándose una especial aproximación entre las posiciones ideológicas de ambos.

En esta línea, las Letters de Blanco, reflejo de su autobiografía religiosa que surge de su necesidad de justificación como converso ${ }^{16}$, están plagadas de referencias a los mecanismos, mezcla de superstición y fanatismo, de los que se sirve la jerarquía eclesiástica en España para controlar en alianza con la monarquía, y más allá de lo político y lo económico, el entramado socio-cultural, incluyendo la prensa y la educación:

Aun las ramas de la ciencia que parecen menos relacionadas con la religión no pueden escapar de la férula de los teólogos, y el mismo espíritu que hizo a Galileo retractarse de rodillas de sus descubrimientos astronómicos todavía obliga a nuestros profesores a enseñar el sistema de Copérnico como una hipótesis (Blanco White, 1977: 106-107)

No es de extrañar pues que Blanco se rebele a favor de la libertad de conciencia como antídoto a esta situación, al lamentar en sus Cartas que "la influencia de la religión en España no conoce límites y divide a los españoles en dos grupos: fanáticos o hipócritas" (Blanco White, 1977: 42). Ya años atrás en El Español planteaba esta necesidad, al preguntarse, en su último número, dentro del artículo "Conclusión de esta obra", si está "el rey Católico dispuesto á conceder lo que el Cristianismo ha dado á sus vasallos -libertad de profesar la religion que á cada qual dicte su propia conciencia" y al advertir de que, de no ser así, "una parte de la nacion se abysme en la supersticion y la ignorancia, y otra en la irreligion mas absoluta, acompañada de los agregados que la hacen mas temible y dañosa -el rencor y la hypocresia"17 (El Español, mayo-junio de 1814: 301 302). Y es que, más allá de su convencional apariencia de periódico político, El Español se revela como una publicación periodística que, si bien no puede considerarse como la primera en difundir la doctrina protestante en español, sí llevó a cabo una tarea fundamental en lo que respecta al aperturismo religioso desde las ideas reformistas frente a la ortodoxia católica, abriendo camino a las pioneras revistas protestantes en español que otro emigrado y, como Blanco, antiguo sacerdote católico, Juan Calderón, pondría en marcha también en Londres, en la segunda mitad del siglo XIX, cuando, ya oficializado el liberalismo español con Isabel II, se aceptarían todas las libertades menos la religiosa (Ruiz-Acosta, 2016: 173). El exilio continuaría siendo así un referente clave en cuanto a la producción de publicaciones prohibidas, pero que también se terminaron difundiendo por España e Hispanoamérica. Nacían de este modo El Catolicismo Neto (18491851) y El Examen Libre (1851-1854). Posteriormente, tras morir Calderón, su viuda, una amiga (Olivia Hargreaves) y la poetisa miss Whately (hija del obispo Whately y ambos también amigos 
de Blanco) pondrían en marcha, contando con Thomas Parker y José Joaquín de Mora, otra figura de la emigración, El Alba (1854-1862).

Desde esta perspectiva, hay que destacar pues el papel que jugará El Español al abogar, de forma decidida, por la separación Iglesia-Estado, al aconsejar a este que "no preste su espada á los que no son de este mundo" (El Español, 30 de abril de 1811: 48). La necesidad de encontrar una solución eficaz a este conflicto es recurrente en la producción periodística y literaria de Blanco. En sus Letters from Spain, al hablar de su marcha de España en plena Guerra de la Independencia, pesando más los motivos de credo que los políticos como "consecuencia de la intolerancia religiosa que amargó su vida”, criticará que, a pesar de que España, en el momento de la publicación de las Cartas, "alardea de una constitución libre, todavía sigue privando a sus hijos del derecho de adorar a Dios según la propia conciencia" (Blanco White, 1977: 36). También desde las páginas de El Español lamentaría que la Regencia existente entonces en su país pretendiera perseguirle, a través de la prohibición de su periódico en tierras americanas, mostrando así "su espíritu intolerante é inquisitorial", con la intención de llegar "hasta este único asilo de la libertad de Europa" (El Español, 28 de febrero de 1811: 350). Es interesante destacar, asimismo, al ahondar en las razones determinantes de la marcha de Blanco de España, que el autor pone especial empeño en recalcar que estas fueron pues de carácter religioso, por la amenaza de ser denunciado ante la Inquisición, incluso por su propia madre, debido al exceso de celo en el que había sido educada ${ }^{18}$. Toda esta problemática se plasmaría también en su obra Practical and Internal Evidence Against Catholicism, publicada en 1825, en el mismo año que The Forest Sanctuary de Felicia Hemans, una crítica del catolicismo reaccionario, inspirada en las Letters de Blanco, que la autora articula a partir de poemas publicados en la revista de Campbell desde 1823 a 1825 (posteriormente irán apareciendo asimismo en ella otros de la misma temática), y que es considerada por la propia Hemans como su mejor trabajo.

Pero, aunque se hacen claramente visibles en Londres, los planteamientos heterodoxos de Blanco venían de antaño. Su propia vocación sacerdotal, según él mismo narra en sus memorias ${ }^{19}$, parece no haber sido nunca real, al iniciar a muy temprana edad su carrera eclesiástica como vía de escape infantil para no verse obligado a trabajar en el negocio familiar y dar también respuesta a su curiosidad intelectual. Moreno-Alonso, en la introducción de su edición de las Cartas de Inglaterra, se refiere, en este sentido, a las "constantes de su vida", destacando que "fue siempre rebelde, desgarradoramente sincero y exigente al máximo consigo mismo" (Blanco White, 1989: $8)^{20}$. A los quince años, su tía le había permitido leer las obras de Feijoo, benedictino que se había atrevido "a atacar el sistema escolástico y a recomendar el estudio experimental de la filosofía 
según los principios de Bacon" (Blanco White, 1975). Su lectura, que atacaba "resueltamente los errores populares con toda la agudeza de su ingenio", le hizo desarrollar una aversión hacia los dominicos, con los que estudiaba, y, sobre todo, hacia todos "los errores establecidos"21. A partir de ahí, sus preocupaciones sobre la Iglesia católica irían in crescendo, especialmente al presenciar rituales como los de los ejercicios espirituales de los jesuitas, que critica en sus Cartas de España y en sus memorias con agudeza descriptiva: "Cualquiera que contemplara a los ejercitantes al salir de la capilla camino de sus habitaciones, se hubiera podido imaginar fácilmente a un grupo de cuarenta o cincuenta prisioneros que acababan de ser condenados a muerte" (Blanco White, $1975)^{22}$.

Si Blanco ya había abordado el complejo tema de la libertad de conciencia en El Español, e incluso en el Semanario Patriótico antes de llegar a Londres, en el periódico de Campbell manifestaría claramente su profunda valoración de la conciencia personal, traducida en una supremacía sobre la ritualidad impuesta por la jerarquía católica, al confirmar su rechazo a los convencionalismos de esta, además de afirmar la primacía del individuo sobre la sociedad como rasgo esencial del liberalismo decimonónico (La Parra, 1998: 32). Precisamente, la referida narración de los ejercicios de los jesuitas sirve para realizar una profunda crítica sobre el rito de la confesión general, asegurando que "el penitente tiene la impresión de que cualquier negligencia suya en esta confesión lo hará culpable de una falta mucho mayor que la de todos sus pecados anteriores", lo que produce "un grave estado de mórbida ansiedad" (Blanco White, 1975)23.

La animadversión de Blanco ante el dogmatismo de la Iglesia católica en España impregnaría también otra de sus publicaciones periodísticas redactadas en español en el exilio inglés, Variedades, ó Mensagero de Londres, concebida para el público de las nuevas repúblicas hispanoamericanas y al frente de la cual estuvo desde su origen, en 1823, aunque su imposibilidad a la hora de no inmiscuirse en lo concerniente a lo político y religioso, según los presupuestos de Rudolph Ackermann como editor, le llevaría a ceder el testigo a José Joaquín de Mora en 1825, año en el que, no obstante, la revista llegaría a su fin. En el último número, fechado en octubre de ese mismo año, aparece sin embargo un artículo de Blanco en el que vuelve a poner de manifiesto su recelo ante la situación de la religión en España, asegurando que, mientras estuvo en Madrid, ni siquiera pudo disfrutar del arte de sus iglesias por no atreverse a entrar en ninguna de ellas (Piñeyro, 1910: 90).

Toda esta crítica a la superstición e intolerancia de la Iglesia católica que realiza Blanco en sus publicaciones, en especial a través de las Letters del New Monthly Magazine, ante la necesidad de poder practicar el ejercicio de la libre conciencia, ejerce una influencia clave en autores 
coetáneos, y naturalmente posteriores, españoles, hispanoamericanos y también ingleses. La hallamos presente, de hecho, en los poemas de Felicia Hemans publicados en la revista por las mismas fechas (desde 1823), como germen de la que constituirá poco después su obra The Forest Sanctuary (1825), ambientada en la conquista española del Nuevo Mundo e impregnada de ese gusto épico de la época que, como en Blanco, va más allá de la tendencia romántica del momento para realzar el ideal patriótico liberal de la que se resalta como una gran nación en la historia, al margen del "poder autoritario y dogmático, funesto por la asfixia intelectual" que impone "la opresión intelectual ejercida por el absolutismo monárquico y la Inquisición" (Llorens, 1979: 401-404). The Forest Sanctuary revela un claro paralelismo con la evolución religiosa de Blanco, mostrándose una ilustrativa reflexión, que arranca con la descripción de un auto de fe de la Inquisición, sobre las ortodoxias asimiladas a la vieja usanza impositiva de los convencionalismos. El monólogo poético de Hemans refleja una historia retrospectiva que nos remonta al siglo XVI, en el que un conquistador español católico se convierte al protestantismo y se exilia por motivos religiosos, como también hace el propio autor sevillano en la vida real aunque este lo haga en Londres y el protagonista de la obra de Hemans en las inhóspitas tierras del Nuevo Mundo, coincidiendo así su transición espiritual, inevitablemente, con la de Blanco. De esta obra literaria de la autora inglesa se desprenden, además, en la línea del periodista y escritor sevillano, como paralelismos esenciales que posteriormente desarrollará la prensa protestante publicada en español desde el exilio, el que identifica catolicismo tradicionalista y pasado, y el que iguala protestantismo liberal y futuro, al profundizar en el análisis crítico de la alianza del Antiguo Régimen entre absolutismo e Iglesia católica.

Todo ello comienza a gestarse en anteriores publicaciones de Hemans en la revista de Campbell, de las que emana un anhelo de perfección espiritual que, como en el caso de Blanco, pasa por un liberalismo religioso, capaz de desentrañar los auténticos valores morales fuera de los encorsetamientos maniqueos del tradicional concepto de culto eclesiástico. Hemans, que de niña dominaba siete idiomas (entre ellos el español) y solía divertirse recitando de memoria capítulos enteros de la Biblia, plasmó en el propio nombre de The Forest Sanctuary (El Santuario del Bosque) un leitmotiv recurrente en sus poemas en prensa, la naturaleza como obra del Creador y, por tanto, vía alternativa ideal de unión con Él mediante el libre pensamiento y frente a las fórmulas convencionales impuestas por la jerarquía eclesiástica en connivencia con el poder monárquico, lo que se destaca en la reseña de The Forest Sanctuary que aparece en 1826 en la misma revista de Campbell: 
That "free thought" which God gave to all men, but which felon despotism even in our time seeks to rifle us of; -that free worship, which, amid the pomp, and hypocrisy, and persecution of nations styling themselves civilized, priests and kings refuse to their fellow men. In that wild asylum, with his altar under the open heaven, he enjoys his faith, and prepares for old age and death (New Monthly Magazine, vol. 17: 42-46).

Frente a lo mundano, lo espiritual, como ya refleja también uno de los poemas de Hemans publicados en el New Monthly Magazine, "The Landing of the Pilgrim Fathers in New England" (noviembre de 1825), en el que contrapone, además, la acción evangelizadora en América de protestantes frente a la de los católicos: "They have left unstain'd what there they found" ("Ellos han dejado sin mancha lo que allí encontraron"24). Y proclama: "Freedom to worship God" ("Libertad para adorar a Dios"), argumentando que, a pesar de las enormes vicisitudes, el exilio, desde la fe, es un pequeño precio que pagar por la libertad religiosa, aunque a cambio se sufra la pérdida de la identidad familiar-nacional. Un precio que, sin embargo, el protagonista de The Forest Sanctuary lamenta con gran pesar, demostrando el amor a su patria, en la que podría morir por su país ("I could had died upon the battle plain"), pero se le niega el derecho a vivir en paz ("but I might not dwell / In thy sweet vales, at peace") (Sussman, 2011: 494-499). Al mes siguiente, en diciembre de 1825, el New Monthly Magazine recoge otro poema, "The Graves of a Household", historia de un amor truncado por la muerte, que sepulta a los enamorados separados y lejos de su hogar, abandonados en la salvaje tierra americana y bajo el mar ("Their graves are sever'd far and wide, / By mount, and stream, and sea"), ambos apartados de su patria, con la que sueñan, siendo además la de él España ("He wrapp'd his colours round his breast, / On a blood-red ñeld of Spain"). Su temática está pues claramente en relación con la de la que Hemans considera su obra cumbre. Anteriormente, en enero de 1824, ya había publicado en la revista de Campbell "The Hour of Death", con otros de los motivos recurrentes de su obra (tempus fugit y carpe diem), destacando la necesidad de estar preparados para la muerte ("But who shall teach us when to look for thee?") como una temática que se torna vital en toda su obra y que abordará, de forma especial, en The Forest Sanctuary, cuya esencia continúa presente en su producción posterior en el New Monthly Magazine. En "The Last Tree of the Forest", poema aparecido en la revista en enero de 1827, vuelve a contraponer así, como ya había hecho en "The Landing of the Pilgrim Fathers in New England", la destructiva acción colonizadora del hombre en el Nuevo Mundo frente a la capacidad de regeneración, también espiritual, de la naturaleza envolvente (“Embower'd from every blast"). No en vano, este eje central de The Forest Sanctuary, la naturaleza que se erige como templo alternativo en el exilio religioso, protagoniza "The Same", otro de los poemas 
publicados en la revista y que, de acuerdo con una práctica habitual, aparece también en otro periódico, el Berrows Worcester Journal (2 de octubre de 1834). En él el bosque se abre como un camino de encuentro con el Creador y los árboles como seres vivos envuelven de nuevo, como en el anterior poema, en un cálido abrazo al exiliado, en contraste con la imagen inerte de su madera cortada por el fuego del fanatismo de la Inquisición: "Confessed a spirit's breath, and heard a teaseless hymn".

\section{CONCLUSIONES}

Como vemos en los textos analizados, la batalla de Blanco, al igual que sucede con Hemans, no es contra la espiritualidad, ni contra la religión, ni contra el cristianismo, ni siquiera contra la propia esencia pura del catolicismo en sí que implica su mensaje cristiano. Claro que es un heterodoxo, pero su lucha es contra la ortodoxia de la interpretación interesadamente errónea que, según se refleja en su obra, la jerarquía de la Iglesia en España hace del credo católico en su propio beneficio. El propio autor insiste en dejar claro en sus memorias, en contra de la lectura antirreligiosa de autores como Goytisolo, que siempre ha creído en Cristo y que, cuando se declaró ateo, fue porque el catolicismo le había provocado un estado de locura (Blanco White; Thom, 1845, vol 1: 242).

La producción periodística de Blanco como referente del exilio decimonónico español en Londres combatió a favor de la causa liberal española no solo a través de los temas puramente políticos, sino también, especialmente, de los de carácter religioso, en los que su implicación personal queda, si cabe, aún más patente, evidenciando el fanatismo y la superstición de la Iglesia católica del momento, frente a la labor de permanente búsqueda de la verdad que realiza el autor, para lo que defiende, como Hemans, la necesidad de libertad de conciencia.

En este sentido, queda manifiesta pues su interconexión con coetáneos ingleses como Felicia Hemans, cuya mejor obra según la propia autora, The Forest Sanctuary, se estructura a partir de la producción periodística previa de Hemans y se nutre de los artículos de crítica religiosa de Blanco, especialmente de sus Letters from Spain y de sus textos en El Español, para mostrar la intolerancia católica y la necesidad de la libertad de credo.

La interrelación anglo-hispana de aperturismo religioso presente en la producción periodísticaliteraria de estos autores abrirá camino a la aparición, también en el exilio londinense, ya en la segunda mitad del siglo, de las primeras revistas protestantes en español, que surgirán también de la iniciativa de emigrados españoles. 
Esta interconexión, asimismo, resultará esencial en el contexto del incipiente rupturismo de la ortodoxia católica e inicio del aperturismo religioso que se reflejará en la obra periodístico-literaria del siglo XIX español.

\section{NOTAS}

${ }^{1}$ Hay diversas reediciones, como la de 1979, aquí utilizada.

2 Fechada en su origen hacia 1877, a pesar de la visión negativa que se expresa por ejemplo en lo referente a Blanco White, constituye un inestimable punto de partida a la hora de investigar la disidencia religiosa de los emigrados liberales en Londres.

${ }^{3}$ La versión original en inglés consultada a través de la colección digital de la British Library Nineteenth Century Collections Online es The Life of the Rev. Joseph Blanco White: Written by Himself, with Portions of His Correspondence (Joseph Blanco White y John Hamilton Thom), edited by John Hamilton Thom (en dos volúmenes) en Londres (John Chapman, 1845). En español, puede verse la traducción de Antonio Garnica: Autobiografía de Blanco-White, publicada por la Universidad de Sevilla en 1975, todo un clásico también existente en versión digital en la Biblioteca Virtual Miguel de Cervantes como Autobiografía de Blanco White / José María Blanco White.

${ }^{4}$ El gobierno británico puso en marcha un sistema oficial de subsidio dirigido por el duque de Wellington, en lo que desempeñó un papel esencial el artículo publicado en The New Times por Blanco White (Sánchez-Mantero, 1993: 85).

${ }^{5}$ La interrelación de los exiliados españoles y los ingleses que les acogieron, entre ellos Lord Holland, resulta decisiva en el posterior auge del liberalismo en España. Lo es además la labor de Lady Holland, no solo como anfitriona de la tertulia política de su hogar, sino también como autora del Spanish Journal, con las impresiones de sus viajes por España (Moreno-Alonso, 1997). Lady Holland fue además confidente de grandes políticos españoles e ingleses de la época (CalvoMaturana, 2004).

${ }^{6}$ Las mujeres que defendían la causa liberal eran conocidas como "liberalas" (Cantos-Casenave, 2016), llamadas así por la policía gaditana de modo peyorativo. Eran perseguidas por su propia causa, pero también al ser culpadas de la actitud liberal de sus compañeros masculinos, lo que refleja el uso de la expresión francesa "cherchez la femme" ("busca a la mujer"), acuñada en 
la novela de Alejandro Dumas Los mohicanos de París (1854). Esta expresión da título a una investigación de Fuentes (2012) sobre las exiliadas y liberales en la Década Ominosa.

${ }^{7}$ El barrio surgió de unos terrenos de la familia Somers, en los que se asentaron los emigrados de Fernando VII y, con anterioridad, aquellos que, como Wollstonecraft, escapaban de los desórdenes y persecuciones a raíz de la Revolución francesa.

${ }^{8}$ La capilla de Saint Aloysius y otras instituciones de caridad deben su existencia a Guy Toussaint Julien Carron, sacerdote francés contrario a la Constitución Civil del Clero, votada en julio de 1790 por la Asamblea Nacional Constituyente tras la Revolución francesa para reformar la Iglesia de Francia.

${ }^{9}$ La obra en la que Dickens recoge estos recuerdos, Casa desolada, fue publicada originariamente en 1853, en plena madurez intelectual del autor.

${ }^{10}$ Así es llamado en el artículo que el Times le dedica en plana editorial el 25 de febrero de 1909, con el homónimo título "A Pilgrim in Religion" (Piñeyro, 1910: 73).

${ }^{11}$ Fiel a la versión original de esta obra, de 1846, puede consultarse la edición en inglés contenida en Dickens, C.; Avery, G. (1995). Asimismo, A Christmas Carol, escrito algunos años antes, en 1843, también es buena muestra de las enseñanzas infantiles de Dickens sobre el auténtico sentido del cristianismo.

${ }^{12}$ La ya citada autobiografía The Life of the Rev. Joseph Blanco White: Written by Himself... muestra la relación epistolar entre Blanco y Hemans, quien en sus cartas le transmite al autor sevillano la admiración por su obra.

${ }^{13}$ El seudónimo hace referencia a su propio nombre: Leocadio deriva de la raíz griega que significa "blanco", mientras que Doblado alude a la característica repetición del apellido del autor en español (Blanco) e inglés (White). Su nombre real, de hecho, era José María Blanco Crespo, habiendo sido el apellido paterno anteriormente White, por su origen irlandés, y habiéndolo cambiado su familia para españolizarlo. Posteriormente, dado su acercamiento a la idiosincrasia inglesa, el autor decide añadir a la traducción española la versión inglesa original, resultando así Blanco White.

${ }^{14}$ Hasta 1972, gracias a la labor de Antonio Garnica, no serían traducidas al español como Cartas de España, con introducción de Vicente Llorens. En 1822 habían sido agrupadas en un volumen publicado en Londres por Henry Colburn. 
${ }^{15}$ Entre los amigos que Felicia encontró entonces en Dublín se hallaba, además del propio Blanco, Lady Morgan, Robert Perceval Graves (tutor de su hijo menor) y su esposa, Sir William Rowan Hamilton y el Arzobispo Whately (Clarke, 1990). Precisamente con él y con su hija, que tendrá una misión fundamental en el impulso de la nueva prensa protestante en español del exilio en Londres, también mantendrá amistad el periodista sevillano, como se manifiesta en las cartas de su autobiografía.

${ }^{16}$ Llorens lo manifiesta así en su introducción a la traducción al español de las Letters, que publica Garnica en 1972.

${ }^{17}$ Respetamos la versión original en esta y otras citas del periódico.

${ }^{18}$ Blanco White, 1975: Nota 20 en el apartado del capítulo III bajo el epígrafe "Salida de España y llegada a Inglaterra (1810)".

${ }^{19}$ El relato autobiográfico de Blanco constituye, a juicio de autores ya clásicos como Piñeyro (1910: 75), el que probablemente sea el documento más relevante para ahondar en su vertiente religiosa como reputado "theological writer" en el exilio inglés.

${ }^{20}$ Reedición del original.

${ }^{21}$ En el apartado del capítulo I en el que habla de su primera juventud.

${ }^{22}$ En el apartado del capítulo I bajo el epígrafe “1790”.

${ }^{23}$ En el mismo apartado.

${ }^{24}$ Traducción propia de la obra de Hemans.

\section{REFERENCIAS}

Ackroyd, P. (1990): Dickens. Londres: Sinclair-Stevenson.

Blanco White, J. M. (1989): Cartas de Inglaterra. Madrid: Alianza Editorial.

- (1977): Cartas de España. Madrid: Alianza Editorial.

- (1975): Autobiografía de Blanco White / José María Blanco White. Biblioteca Virtual Miguel de Cervantes. Recuperado de http://www.cervantesvirtual.com/obra/ autobiografia-de-blanco-white--0/

Blanco White, J.; Thom, J. H. (1845): The Life of the Rev. Joseph Blanco White: Written by Himself, with Portions of His Correspondence; Edited by John Hamilton Thom, vol. 1, 2 y 3. Londres: John Chapman. 
Calvo-Maturana, A. J.: Elisabeth Holland: portavoz de los silenciados y cómplice de un tópico. Cuadernos de Historia Moderna, vol. 29 (2004), pp. 65-90. Recuperado de http://revistas. ucm.es/index.php/CHMO/article/view/CHMO0404110065A/22294

Cantos-Casenave, M.: Reaccionarias y "Liberalas” en Andalucía (1814-1835). En BUTRÓN, G.; RAMOS-SANTANA, A. (eds.) (2016): Cádiz, escuela política: Hombres e ideas más allá de 1814. Madrid: Sílex, pp. 241-276.

Clarke, N. (1990): Ambitious Heights: Writing, Friendship, Love: The Jewsbury Sisters, Felicia Hemans, and Jane Welsh Carlyle. London: Routledge.

Coletes, A.; Laspra, A. (eds.) (2013): Libertad frente a tiranía: Poesía inglesa de la Guerra de la Independencia (1808-1814). Antología bilingüe. Madrid: Espasa.

Colledge, G. (2012): God and Charles Dickens: Recovering the Christian Voice of a Classic Author. Ada: Baker Books.

Dickens, C. (2012): Casa desolada. Madrid: Valdemar.

Dickens, C.; Avery, G. (1995): Holiday romance and other writings for children. Londres: Everyman.

Durán De Porras, E.: De la euforia a la decepción: la prensa inglesa ante el levantamiento español. El Argonauta Español (Junio 2008), n 5 . Recuperado de

\section{http://argonauta.revues.org/835}

Durán-López, F.: Desestabilizando ortodoxias: José María Blanco White, traductor. En LAFARGA, F.; PEGENAUTE, L. (eds.) (2016): Autores traductores en la España del siglo XIX. Kassel: Reichenberger, pp. 78-92.

- (2015): Versiones de un exilio: Ios traductores españoles de la casa Ackermann (Londres, 1823-1830). Madrid: Escolar y Mayo Editores.

-: El destierro infinito de Blanco White en la mirada de Juan Goytisolo. Revista de literatura, vol. 72 (2010), n 143, pp. 69-94.

—: Ideas que imprimen carácter: narración, retrato y otras maniobras de distracción en la 'Historia de los Heterodoxos'. Boletín de la Biblioteca de Menéndez Pelayo (2006), nº 82, pp. 353-391.

—: (2005): José María Blanco White o la conciencia errante. Sevilla: Fundación José Manuel Lara. Fuentes, J. F.: Cherchez la femme: Exiliadas y liberales en la Década Ominosa (1823-1833). Historia Constitucional (Septiembre 2012), n 13, pp. 383-405. Recuperado de http://www. historiaconstitucional.com

—: Geografía del liberalismo español en la Década Ominosa: emigración política y exilio interior. En ALBEROLA, A.; LARRIBA, E. (eds.) (2010): Las élites y la "Revolución de España" 
(1808-1814). Estudios en homenaje al profesor Gérard Dufour. Alicante: Universidad de Alicante-Université de Provence-Casa de Velázquez, pp. 309-331.

—: Imagen del exilio y del exiliado en la España del siglo XIX. Ayer, vol. 2 (2002), nº 47, pp. 35-36. Fuentes, J. F.; Garí, P. (eds.) (2014): Amazonas de la libertad: Mujeres liberales contra Fernando VII. Madrid: Marcial Pons.

Garnica, A.: Las razones de un exilio. En MORENO-ALONSO, M. (2002): José María Blanco White y el problema de la intolerancia en España. Sevilla: Caja San Fernando, pp. 51-66.

-: El heterodoxo Blanco White. Archivo hispalense: Revista histórica, literaria y artística, vol. 76 (1993), $n^{\circ} 231$, pp. 137-154.

Goytisolo, J.; De Ory, M. T.: José Blanco White (España y la independencia de América). República de las Letras: revista literaria de la Asociación Colegial de Escritores (Junio 2011), nº 122, pp. 113-126.

La Parra, E.: Los inicios del anticlericalismo español contemporáneo. En LA PARRA, E.; SUÁREZ, M. (eds.) (1998): El anticlericalismo español contemporáneo. Madrid: Biblioteca Nueva.

Ledger, S.; Furneaux, H. (eds.) (2011): Charles Dickens in Context. Cambridge: Cambridge University Press.

Loyola, D., Flores, E. M. (eds.) (2018): La voz del desterrado. Antología de la literatura española del exilio en la primera mitad del siglo XIX. Madrid: Guillermo Escolar.

Llorens, V. (1979): Liberales y románticos. Una emigración española en Inglaterra (1823-1834). Madrid: Castalia.

Menéndez Pelayo, M. (2007): Historia de los heterodoxos españoles. Madrid: Homo Legens.

Moreno-Alonso, M.: José María Blanco White: Obsesión por España. La Aventura de la historia (2014), n Extra 25 (2014), pp. 18-25.

—: La tentación inglesa, 1823-1833. En PEÑA DÍAZ, M. (2009): Las Españas que (no) pudieron ser: herejías, exilios y otras conciencias (s. XVI-XX): Huelva: Universidad de Huelva, pp. 147-156.

— (1997): La forja del liberalismo en España. Los amigos españoles de Lord Holland (1793-1840).

Madrid: Congreso de los Diputados.

- (1989a): La generación española de 1808. Madrid: Alianza.

-: La masonería española ante Blanco White. En FERRER, J. A. (1989b): Masonería, política y sociedad, vol. 1. Zaragoza: Centro de Estudios de la Masonería Española, pp. 341-366.

—: Las ideas políticas de 'El Español'. Revista de estudios políticos (Mayo-Junio 1984), n 39, pp. 65-106. 
Muñoz-Sempere, D.: Góticos, traductores y exiliados: la literatura sobre la Inquisición española en Inglaterra (1811-1827). Cuadernos de Ilustración y Romanticismo (2005), n 13, pp. 141-169.

Piñeyro, E.: Blanco White. Bulletin Hispanique, vol. 12 (1910), nº 1, pp. 71-100.

Reyes-Cano, R.: José Blanco White y su visión de la historia literaria española. En REYESCANO, R. (2001): De Blanco White a la Generación del 27. Estudios de literatura española contemporánea. Sevilla: Universidad de Sevilla, pp. 17-33.

Rubio, D.; Rojas, A.; Fuentes, J. F.: Aproximación sociológica al exilio liberal español en la Década Ominosa (1823-1833). Spagna Contemporanea, vol. 7 (1998), nº 13, pp. 7-20.

Ruiz-Acosta, M. J. (ed.) (2016): La Prensa Hispánica en el exilio de Londres (1810-1850). Salamanca: Comunicación Social.

Saglia, D. (2000): Poetic Castles in Spain: British Romanticism and Figurations of Iberia. Amsterdam: Rodopi.

Sánchez-Mantero, R.: París, el exilio liberal. En MARTíNEZ-LÓPEZ; F., CANAL, J.; LEMUS, E. (eds.) (2010): París, ciudad de acogida: el exilio español durante los siglos XIX y XX. Madrid: Marcial Pons, pp. 41-54.

—: Exilio liberal e intrigas políticas. Ayer, vol. 2 (2002), n 47, pp. 17-34.

-: El exilio político en tiempos de Blanco White. Archivo hispalense: Revista histórica, literaria y artística, vol. 76 (1993), n² 231, pp. 75-88.

- (1975): Liberales en el exilio. (La emigración política en Francia en la crisis del Antiguo Régimen). Madrid: Rialp.

Seco-Serrano, C.: La España de Blanco White. Archivo hispalense: Revista histórica, literaria y artística, vol. 76 (1993), n² 231, pp. 17-30.

Sussman, Ch.: Epic, Exile and the Global: Felicia Hemans's The Forest Sanctuary. NineteenthCentury Literature, vol. 65 (2011), $n^{\circ}$ 4, pp. 481-512.

Sweet, N.: The Forest Sanctuary: The Anglo-Hispanic Uncanny in Felicia Hemans and José María Blanco White. En ALMEIDA, J. M. (ed.) (2010): Romanticism and the Anglo-Hispanic Imaginary. Amsterdam: Rodopi, pp. 159-182.

Taylor, B.: Los exiliados españoles y portugueses y los impresores londinenses, 1803-1833. En MUÑOZ-SEMPERE, D.; ALONSO, G. (eds.) (2011): Londres y el liberalismo hispánico. Madrid: Iberoamericana, pp. 275-279.

Varela, J.: La prensa liberal española en Londres y París ante la Constitución de Cádiz. 18241830. Cuadernos de Ilustración y Romanticismo (2016), n² 22, pp. 329-338. 
Benítez-Alonso, E. M. El exilio español en Londres: Heterodoxias de religión y prensa. Blanco White y Felicia Hemans.

- (2005): El conde de Toreno. Biografía de un liberal (1786-1843). Madrid: Marcial Pons.

Walder, D. (1981): Dickens and religion. Londres: Allen \& Unwin.

Watts, C. T. (1976): The English novel. Londres: Sussex Books. 